\title{
The Discussion on Multi-channel Distribution System under B2C E-commerce Mode
}

\author{
Ming Li \\ JiLin Business And Technology College, ChangChun, China \\ 120857715@qq.com
}

Keywords: Supply Chain, B2C,Electronics Market, Multi-channel

\begin{abstract}
With the rapid development of network technology and E-commerce, many enterprises open up the electronics market to sell products to the end consumers directly while maintaining the traditional retail channels. In recent years, more and more attention is paid to the studies on multi-channel distribution system under B2C E-commerce in the enterprise community and academic community. This paper tracts the research results of multi-channel distribution system under B2C E-commerce mode in recent years and reviews the overseas and domestic research status from the multi-channel structural arrangements and pricing, multi-channel conflict and coordination, multi-channel operations management and finally proposes the future research directions in this field.
\end{abstract}

\section{Introduction}

With the increase of B2C global turnover yearly and the strength of consumers' awareness of network consumption, there are many famous companies in the world, such as HP, Wal-Mart, Haier, etc, opening up the $\mathrm{B} 2 \mathrm{C}$ direct sales channel to sell products online as well as maintaining the traditional sales channels. In recent years, the hybrid dual-channel combined by traditional channel and B2C E-commerce that takes the electronic market as a separate distribution channel and sells products directly to end consumers through electronics market has attracted broad attention from the enterprise community and scholars. Faced with the rapid development of E-commerce, how to arrange the hybrid mode based on B2C E-commerce model, how to price under hybrid channel environment, whether the opening of electronic channels will bring conflicts to the traditional channels and how to coordinate and operate the multi-channel distribution system will be the research priorities of many scholars. In this paper, the main research problems for the above issues in recent years are summarized so as to propose the main research directions in the future.

\section{Overview of Multi-channel Distribution System under B2C E-commerce Model}

Distribution system refers to the chain structure or net structure composed by the connection between the product manufacturer, distributor (or dealer), warehouse and a member in the shopkeeper and the upstream and downstream members through the logistics and flow of members. Many scholars study the modeling and optimization of the traditional two-stage supplying chain distribution system and the coordination and motivation of distribution channels, the main channel structures are as follows:

The distribution channel composed by one manufacturer and one retailer. Since this channel is simple in structure and easy to deal with, many researchers have proposed the coordination strategies to reduce the lower channel efficiency and maximize the profits in supply chain, such as the wholesale price contract, repurchase contract, revenue sharing contract and quantity flexibility contract and Cachon and Tsay have reviewed this aspect in detail.

The distribution channel composed by a single manufacturer and multiple retailers. Many scholars consider that the manufacturers have sufficient capacity in production and different retailers serve different customers and thus there is no competition between retailers; they also discuss the competition between two retailers for the joint customers through price and non-price 
factors (such as services) in the distribution system and give out the coordination strategies for the manufacturers.

The distribution channel composed by multiple manufacturers and one or more retailers. This channel structure appears to be complex and introduces competition at the manufacturer level, however, what is discussed is still the single channel structure. Choi was the first person to discuss that the products of two manufacturers were alternative if selling by a common retailer and then the condition was extended to that the manufacturers of alternative products sold the products through two different retailers, which mainly discussed the impact of different channel structure and product difference on the correlation between channels[1].

\section{Structural Arrangement and Price Competition of Hybrid Channel under B2C E-commerce Model}

With the development of network technology, the arrangement of hybrid channel structure under B2C E-commerce model has caused many experts' attention. Generally speaking, there are three sponsors entering into the electronics market: (1)Manufacturers;(2)Reign retailers; (3)New E-commerce retailers specializing in the online sales. According to the different subjects who open up the electronics market, the hybrid channel structures under B2C E-commerce model are simplified into the four types in figure 1 in this paper after analyzing the hybrid channel structure studied in previous literature.

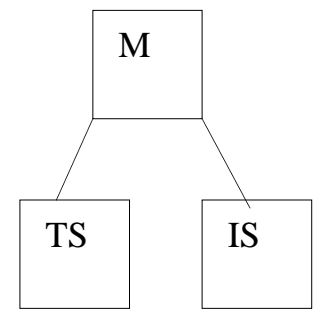

(1)Dispersive multi-channel

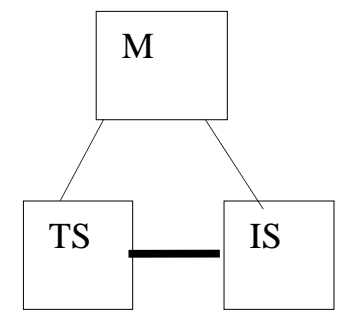

(2) Horizontally integrated multi-channel

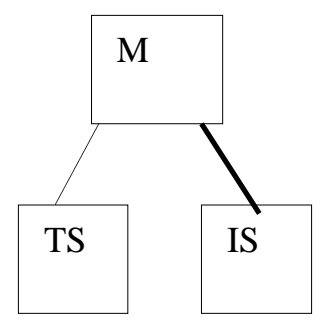

(3)Partly integrated multi-channel

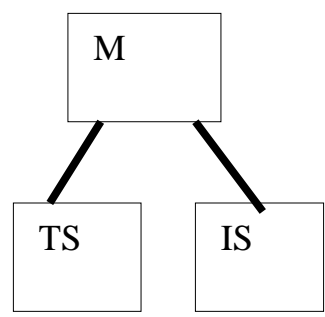

(4)Vertically integrated multi-channel

Notes: M- Manufacturer; TS-Traditional Store; IS-Internet Store; the full line means the integrated relationship; the dotted line means the independent relationship

Figure 1 Structure Diagram of Multi-channel Supply Chain under E-commerce Environment

Dispersive multi-channel. This channel structure primarily refers to that the E-commerce retailers specializing in online retails enter into the electronic market to compete with the traditional retailers. A typical example is the online bookstore of Amazon.com. Dispersive channel structure is similar to the channel distribution combined by a manufacturer and two retailers . However, the channel structure composed by one manufacturer and multiple retailers have been researched in the previous literature which discusses the competition among retailers by price or service, the competition between retailers and end customers or the supply shortage due to the insufficient resource of manufacturer and studies the manufacturer's price and coordination strategies.

In the mixed channel under B2C E-commerce model, because of totally different retailer types, that are E-retailers and traditional retailers, the consumers can purchase goods from different channels and their selection strategies are also different. The assumptions of the existing literature describe the difference between the E-commerce retailers and traditional retailers through Hottly linear market or circumferential market; there is no travel cost incurred in electronics market, however, there is in the traditional retail shops. Supposing that consumers and $\mathrm{N}$ traditional retailers are evenly distributed on the circumference whose perimeter is 2 and the E-commerce retailers are located in the center, use the Game Theory to analyze the price competition between the traditional channel and the online channel opened up by the third party so as to discuss the impact of market 
information and market coverage on equilibrium outcome. It is found that when the product is not suitable for the selling in the electronic channel, it is unavailable to provide worthy information to all consumers even if the information cost is zero, and meanwhile, the profits may be lowered due to the high market coverage (the more the number of retailers in the market) .

Horizontally integrated multi-channel. Horizontal integrated hybrid channel refers to that the traditional incumbent retailers open up the electronic market while maintaining the traditional retail channels and apply the mixed dual channel distribution strategy. The typical example is that the retail giants of Wal-Mart and Carrefour open their own online stores whiling adopting the traditional retail stores to sell products. After the disillusion of this channel structure due to the electronic commerce bubble in 1999, the number of pure E-commerce retailer reduced, however, the traditional retailers opened up the electronic channels and the Bricks-and-Clicks channel structure began to rise.

Partly integrated multi-channel. While maintaining the traditional retailers to sell their products, the manufacturers also open up the direct online channel and adopt the mixed multi-channel distribution strategy; the commodities can be sold directly to the consumers from the manufacturers through the direct online channel so as to compete with the retailers[2]; many famous manufacturing enterprises, such as IBM and HP have adopted this channel structure.

The standard assumption of the researching question under this channel structure is that: it is a two-stage supply chain composed by a manufacturer and a retailer, a single product is considered and the same products are sold in different channels; the traditional channel and electronic channel compete for consumers through price or service, the manufacturer, as the leader of Stackelberg game, determines wholesale price and the sales price of electronic channel at the same time and the retailer observes the manufacturer's pricing strategy in order to decide whether to continue selling their products and how to price; the manufacturer, as the leader of Stackelberg Game, feeds back the retailer's price behavior so as to arrange the channel structure and set the price.

Vertically integrated multi-channel. There was not enough attention paid to the vertically integrated multi-channel structure in the past literature due to the few business models in practice. Weon considered about this channel structure, compared the profits of these four channel structures and found that the introduction of electronic channel might increase the channel profits, the manufacturers would gain the greatest profit in vertically integrated mixing channel and the consumer's surplus would also increase because the market coverage was expanded due to the introduction of electronic channels.

\section{The Multi-channel Operation Strategy under B2C E-commerce Model}

The study on the operating field of multi-channel distribution system under the B2C E-commerce environment is concentrated on the production strategy or inventory allocation strategy during the inventory shortage under the multi-channel environment and the channel ordering; the modeling methods of traditional supply chain operation and management are used to model, including the probability theory, mathematical programming, optimization and game theory[3].

The first situation is the manufacturer's production strategy when there is no stock transferring among the channels, for example, Xu Jiawang considers that multiple manufacturers can sell their products to multiple end-consumers while selling directly to customers through online electronic market, therefore, the multi-objective robust operation model under uncertainty demand is established to find the optimal production strategy for manufacturer by examples. Then the Cournot competition model among manufacturers under the multi-channel system is established to achieve the optimal production strategy for manufacturer. The inadequacy is that data is derived from simulation data instead of actual data.

In the second situation, there is stock transferring among channels; supposing that all the prices are exogenous and the demands are stochastic, there is a certain probability for the customer to transfer to another channel when finding that a channel is out of stock and thus the newsboy model is used to determine the balanced inventory level. When a channel is out of stock and cannot meet 
the demand, there is a certain probability to transfer to another channel; considering that the manufacturer's production can be infinite and finite, it is acquired that the manufacturer may cut retail order quantity and give the basic conditions for the cutting under the condition of sufficient production.

\section{References}

[1] J.J. Gao, Y.J. Wang and Y.J. Guo. The Profit Model of Multiple Product Distribution System. Method of System Engineering Theory, 2005,14(2):124-130.

[2] T.Y. Shen .The Design and Implementation of B2B E-commerce Platform Based on WEB. Beijing: Tsinghua University,2004.

[3] C.Q. Lou , X.W. Gui and X.D. Wang. Report on E-commerce Development of Wuhan Urban Agglomeration. Beijing: Science Press, 2009: 25-28 